International Journal of Instruction e-ISSN: 1308-1470 • www.e-iji.net

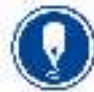

July $2021 \bullet$ Vol.14, No.3

p-ISSN: 1694-609X

pp. 309-326

Article submission code: 20200707015254
Received: 07/07/2020

Revision: 15/12/2020
Accepted: 09/01/2021

OnlineFirst: 06/05/2021

\title{
What Differences between Parents 'and Teachers' Views about their Relationships in Québec (Canada)
}

\author{
Enkeleda Arapi \\ Laval University, Canada, enkeleda.arapi@fse.ulaval.ca
}

Christine Hamel

Laval University, Canada, christine.hamel@fse.ulaval.ca

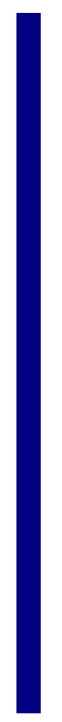

\begin{abstract}
Over the past 50 years, a consensus emerged from the scientific literature regarding the positive effects of school, family and community partnerships on school achievement. However, researchers noted that the implementation of these partnerships still gives rise to tensions on the ground. This research tackled with how parents and teachers get involved in the school-family-community cooperation process to support pupils at the elementary school (age 6 to 12). The goal of this paper is to compare on the one hand, the parents' views in their narratives on parents and teachers practices, and on the other hand, the teachers' views in their narratives on parents and teachers practices as well, to gain insight on the tensions characterizing these partnerships and on the possible solutions set forth by these actors. To this end, the empirical analyses are based on a approach with qualitative interviews among 14 teachers and 45 parents of pupils at six elementary schools in the Greater Quebec City area. To this end, interviews were conducted with 14 teachers and 45 parents of pupils at six elementary schools in the Greater Quebec City area. The results suggest that practices such as school-family communication or homework are privileged among parents and teachers. The analyses also suggest that parents and teachers diverge over the tools teachers use to support parents involvement.
\end{abstract}

Keywords: parental involvement, teacher involvement, school-family relationship, practices, teachers

\section{INTRODUCTION}

Reflections on the development and implementation of school, family and community (SFC) partnerships are not new. The knowledge, practices, competencies and actions of the actors involved in these partnerships have been investigated, analyzed and reflected on in the scientific literature and in political and public debates five decades now. The recommendations of researchers (Deslandes, 2020; Epstein, 2011; Wilder, 2014) and educational policies have emphasized the need to foster partnership approaches among 
these actors, namely, school administrators, school staff, teachers, parents and various social actors (OECD, 2010).

However, while SFC partnerships have been advocated and their positive effects proven, the debate over them is still ongoing. As Larivée (2012) pointed out, simply promoting school-family partnerships does not necessarily lead to their improvement. In the same vein, Deslandes \& Barma (2015) noted that the question remains as to "whether parental involvement is really desired" (p. 31, trans.) even though research results have shown its positive effects. Kanouté \& Calvet (2008) observed that "unilateralism on the part of schools in defining the main terms of school-family partnerships" (p. 172, trans.) does not foster parental involvement and, in fact, spurs parents to adopt a posture of resistance and distance themselves from the school. According to these authors, parents feel that their involvement at school, particularly in school councils, is only figurative, as their opinions are not really taken into account. On the other hand, Larivée (2011) reported that parents appear to appreciate all forms of school involvement. In fact, many studies dealing with SFC partnerships have investigated and analyzed parental involvement (PI); however, few studies have examined teacher involvement (TI). This paper aims to address this gap in the literature by analyzing and comparing together forms of PI and TI.

\section{Epstein's Model: the Theoretical Basis for SFC Partnerships}

Epstein's model was used in this study to operationalize the practices of the actors relating to SFC partnerships. The principles of this model include 1) shared institutional responsibility, 2) an emphasis on coordination, cooperation and complementarity between the school and family, and 3) fostering communication and collaboration between these two institutions. In this model, the school and family share responsibility for a pupil's socialization and education.

Thus, Epstein's model emphasizes coordination, cooperation and complementarity between the school and family, and the importance of fostering communication and collaboration between these two institutions. Epstein's collaborative model defines the roles, actions, and interactions of parents and educators. Epstein defines parental involvement through the following dimensions: parenting, learning at home, volunteering, communicating with the school, decision making and collaborating with the community. The roles, actions and relationships operating within these dimensions are described as principal components of PI.

While the roles of teachers and parents can differ, both share responsibility for student success in school. Many authors (Deslandes 2020; Hoover-Dempsey et al., 2010) have highlighted the leadership role played by teachers when it comes to implementing activities fostering SFC partnerships. The Quebec Education Act specifies that it is the school's responsibility to inform parents regarding their child's academic progress and conduct, and encourage parents' participation in their child's schooling. Thus, based on these observations and the principles stemming from Epstein's model, it can be asserted that teachers have the competencies and authority needed to motivate, encourage and stimulate PI. In this study, TI is defined as proactively engaging with parents through various activities and behaviours aimed at promoting PI at school and at home. 


\section{Parental and Teacher Involvement}

School, family and community partnerships are built through interactions between parents and teachers. These partnerships are only possible when both of these actors get involved. The forms of PI are multiple and diverse and play out in two different environments: at home and at school (Deslandes, 2020; Karbach et al., 2013).

Parents can provide support for learning at home. According to many researchers, this dimension is identified by parents as an important means of supporting their children's school achievement, and by teachers as a means of involving parents (Deslandes \& Bertrand, 2005; Larivée, 2012). However, there is an ongoing debate regarding the effectiveness or optimal type or quantity of homework, and there is disagreement between the two partners on this subject (Hill \& Tyson, 2009; Wilder, 2014). Thus, Deslandes et al. (2008) suggest that teachers need to personalize and individualize their teaching and communicate to parents what their children have learned. This appears to be even more relevant in the Quebec context, where teachers have had to review and diversify their teaching practices following an education reform (Deslandes \& Rivard, 2011). These researchers hypothesize that many parents do not understand the new teaching and assessment practices. Moreover, the student population in Quebec is heterogeneous (Deslandes, 2020) with cultural differences among parents leading to tensions in school-family relations, as teachers are tasked with helping parents become more effectively involved in their children's schooling. As noted by Prévot (2008), parents would like to be involved in their children's schooling but do not always know how best to support them in this regard. Hence the importance of the teacher's role in guiding and encouraging PI at home and at school.

PI at school can take the form of volunteering or participating in the school council (SC). These forms of PI have been found to have positive, albeit statistically weak, effects on student achievement (Hill \& Tyson, 2009). However, these forms of PI at school are not possible for all parents due to incompatible schedules, work constraints, family structure, etc. (Larivée, 2012). Other factors can also influence these forms of involvement at school. For example, Larivée (2011) noted that there appears to be a lack of knowledge or uncertainty regarding parental involvement in community-based activities, and teachers may even show a lack of concern for these types of activities.

Indeed, the critical role played by teachers' practices and attitudes in terms of fostering PI has been highlighted by several researchers (Hoover-Dempsey et al., 2010; Epstein \& Van Voorhis, 2001). Thus, a teacher's openness to PI constitutes an important condition for the construction of parent-teacher relationships. However, teachers do not always readily accept the presence of parents at school and even less so in the classroom. Some authors (ex. De Saedeleer, Brassard \& Brunet, 2004) found that teachers and school administrators tend to assign traditional roles to parents, consisting mainly in helping children with learning at home, while only partially recognizing the need for their involvement at school. Teachers consider the supportive role of parents important (Addi-Raccah \& Grinshtain 2017), but also think parents « should express their support towards school and teachers and in this way support the mandate of the school »pg 333 (Bæck 2010). Teachers reckon the importance of PI, but it seems that there is some 
ambiguity in their relationship with parents. Thus, teachers are reluctant and somewhat reserved about the idea of involving parents in their children's learning (Dor \& RuckerNaidu, 2012). Others see parents as a source of problems, as they report strained and negative relations with parents, lack of trust and recognition of their work on the part of parents (Addi-Raccah \& Grinshtain 2017). These attitudes can have an effect on PI and especially those of educated parents who tend to intervene at school when they deem it necessary, to keep an eye on the teacher and to express opinions on pedagogic issues and teaching methods (Bæck 2010). This fearful attitude and lack of openness on the part of teachers causes parents to feel they are perceived as intruders (Larivée, 2012; Kanouté \& Calvet, 2008). This feeling may also be influenced by the desire of teachers to perpetuate the traditional idea that parents and schools are separate and have different roles and responsibilities (Addi-Raccah \& Grinshtain 2017; Dor \& Rucker-Naidu, 2012).

As many authors have pointed out, (Epstein, 2011; Deslandes, 2020; Lewis, Kim and Bey, 2011), the way teachers encourage parental involvement affects parents' decision regarding whether or not to get involved in their child's schooling. Thus, parents who are encouraged to read or do homework with their children tend to be more involved at home and at school (Deslandes \& Bertrand, 2005). However, parents from all backgrounds report not often being invited to get involved in this way (Deslandes et al., 2008), except when a child is having trouble at school.

This brings us to the question of family-school communication. The frequency and quality of exchanges between parents and teachers play a critical role in the construction of collaborative parent-teacher relationships (Karsenti, Larose \& Garnier, 2002; Lewis, Kim \& Bey, 2011). High-quality communication allows for a relationship of trust to be established between these actors and lessens the incompatibilities between the expectations of the school and family environments. Similarly, parent-child discussions can contribute significantly to school achievement (Boonk, Gijselaers, Ritzen, \& BrandGruwel, 2018). In fact, these parenting practices are beneficial both for children, who develop better self-esteem and greater social competence and achieve better results at school, and for parents, who report, among other benefits, higher feelings of efficacy and positive affects in the parent-child relationship (Lamboy \& Guillemont, 2014).

Thus, as regards SFC partnerships, grey zones remain. As suggested by Boulanger, Larose, Grenier, Doucet, Coppet \& Couturier (2014), these partnerships should not be analyzed monolithically, but rather as "a space for open debate where the dialectical tensions between the dominant discourse and marginal discourse come into play" (p.132, trans.). Hence the importance of considering and comparing the actions and know-how of, and relationships between, both sets of actors involved. To our knowledge, few studies have put into dialogue the perceptions of parents and teachers about their practices related to SFC collaboration. This study thus aimed to compare the discourse of parents and teachers in order to better understand SFC partnerships. To this end, we set out to answer the following questions: What are the practices developed by teachers and parents that encourage or not cooperation between them? Are there divergences and convergences between parents and teachers in the context of their 
cooperation? What are the elements of a efficient cooperation according to parents and teachers?

\section{METHOD}

The purpose of this study was to understand how parents and teachers get involved in the school-family-community cooperation process to support pupils at the elementary school. To do this, the qualitative approach is used. Data collection for the study included interviews about the parents and teachers. Data analysis was informed by a content analysis (Miles, Huberman \& Saldana, 2013). The characteristics of the participants, instruments, procedure and data analysis are presented in the following sections.

\section{Participants}

The sites involved in this study were six elementary schools in the Greater Quebec City area. Hired from these schools, 14 teachers and 45 parents participated in the interviews. These parents' children attended the classes of the 14 teachers who participated in the research: there is thus a relationship between the parents and the teachers, with the pupils at the heart of this relationship. This constitutes what is referred to as a convenience sample (Karsenti et al., 2002), the subjects having participated on a voluntary basis following a request by the researcher.

Parent participants: The sample includes 45 parents of elementary school pupils. There are 14 parents whose child attends 1 st or $2^{\text {nd }}$ grade (pupils aged 6-7), 19 parents whose child attends $3 \mathrm{rd}$ or 4 th grade (8-9 years old) and 12 parents whose child attends 5 th or 6 th grade (10-11 years old). Most of the parent respondents $(n=34)$ were mothers, while just over a quarter of respondents were fathers $(n=11)$. Most of the parents came from intact families $(n=42)$. Most of the mothers $(n=20)$ hold an undergraduate degree, a secondary school or college degree $n=11$ a post-graduate university degree $n=14$. Fathers $(n=12)$ held an undergraduate degree, a secondary school or college degree $n=15$, a post-graduate university degree $n=18$. Moreover, most of the families $(n=27)$ had an annual gross family income of $\$ 100,000$ or more, with a small minority of families $(n=2)$ grossing less than $\$ 40,000$ per year.

Teacher participants: The sample also included 14 elementary school teachers. Most of the teacher participants were women $(n=12)$. They taught in Grades 1 and $2(n=5)$, Grades 3 and $4(n=5)$ and Grades 5 and $6(n=4)$. Most of the teachers $(n=9)$ had over 20 years' experience.

\section{Instruments: Semi-Structured Interviews}

The data were collected through semi-structured interviews conducted with the parent and teacher participants, with both sets of interviews having the same goal, namely, to collect these actors' representations regarding their involvement in parent-teacher partnerships, to gain insight into the meaning they gave to these partnerships. Our goal was thus to investigate the forms of parental and teacher involvement. Moreover, we aimed to bring out the actors' perceptions of the ideal school-family relationship.

The interview grid followed the same structure for both parents and teachers so as to bring out the similarities and differences in the perceptions and forms of involvement 
reported by these two sets of actors. More specifically, the interviews investigated five main themes, namely, teacher involvement, parents' perceptions of teacher involvement, parental involvement, teachers' perceptions of parent involvement and the ideal schoolfamily relationship. Table 1 below displays examples of themes, subthemes and question types.

Table 1

Themes and sub-themes in semi-structured interviews

\begin{tabular}{lll}
\hline Theme & Sub-theme & Questions \\
\hline \multirow{4}{*}{ TI } & $\begin{array}{l}\text { Means of } \\
\text { communication used }\end{array}$ & What are your means of communication with parents? \\
\cline { 2 - 3 } & $\begin{array}{l}\text { Forms of volunteering } \\
\text { encouraged }\end{array}$ & $\begin{array}{l}\text { What form of parental involvement do you favor directly in } \\
\text { your class? }\end{array}$ \\
\cline { 2 - 3 } & $\begin{array}{l}\text { Means of encouraging } \\
\text { parental support }\end{array}$ & $\begin{array}{l}\text { What means do you use to encourage the help / support of } \\
\text { parents in learning? }\end{array}$ \\
\cline { 2 - 3 } & $\begin{array}{l}\text { Means of encouraging } \\
\text { involvement in SC }\end{array}$ & $\begin{array}{l}\text { How do you encourage parents to participate in the various } \\
\text { instances of the school? }\end{array}$ \\
\cline { 2 - 3 } & Community resources used & How do you perceive the collaboration with the community? \\
\hline \multirow{4}{*}{ PI } & Communicating & What are your means of communication with the teacher? \\
\cline { 2 - 3 } & Volunteering & What kind of volunteering do you participate in? \\
\cline { 2 - 3 } & Learning at home & How do you help your child at home? \\
\cline { 2 - 3 } & Decision-making & In which instances of the school do you participate? \\
\cline { 2 - 3 } & $\begin{array}{l}\text { Collaborating with the } \\
\text { community }\end{array}$ & $\begin{array}{l}\text { What community resources do you use that can contribute } \\
\text { indirectly to your child's learning? }\end{array}$ \\
\hline SF & Ideal SF relationship & $\begin{array}{l}\text { For you, what will be the ideal relationship between parents } \\
\text { and school to support student success? }\end{array}$ \\
\hline
\end{tabular}

\section{Procedure}

To carry out this study, we invited 12 primary schools and six of them responded positively to our invitation. The principals of these schools forwarded the invitations to the titular teachers. Teachers who volunteered to participate in the research forwarded the invitations to parents. The interviews were recorded and then written (verbatim). One limitation of this procedure is to rely on the volunteering of teachers and parents. Teachers and parents who agreed to participate in the study were met individually.

\section{Data Analysis}

Our data analysis was based on content analysis, a form of qualitative analysis designed to describe any communication content for the purpose of interpreting it (Miles, Huberman \& Saldana, 2013). It involves a systematic approach with coding, categorizing and interrelating the collected discourses to identify the ideas and representations of the interviewees.

The successive steps of the analysis include pre-analysis, coding, categorization, interrelating ideas and finally the elaboration of conclusions. During pre-analysis, the interviews conducted with the teachers and parents were transcribed in full. Then during coding, the content of the verbatim was coded so as to detect the emergence of relevant themes for the objectives of the specific research and the theoretical framework (Miles, Huberman \& Saldana, 2013). Coding was conducted screening for significant words, lines or paragraphs as units of meaning in the whole verbatim (Krippendorf, 2004) and was conducted using the TAMS software. The coding grid was then filled out and 
enriched with new codes emerging from the meaningful passages in the collected discourse, during the reading of the individual interview transcripts. Following the preliminary analysis of the collected data, using our research questions as a basis, the codes were grouped together into categories. An analytical grid was constructed using predetermined themes based on our literature review and theoretical framework.

The key ideas identified in the parents' speech are organized according to five themes: 1) Teacher involvement, 2) Parents' perceptions of teacher involvement, 3) Parent involvement, 4) Teachers' perceptions of parent involvement, and 5) Ideal school-family relationship. The first four themes include five codes each describing SF communication, learning activities and supervision at home, volunteering, decisionmaking and collaboration with the school. More specifically, the first two themes illustrate the practices made by the teacher to involve the parents of his or her class (theme 1) and the parent's perceptions of the practices of his child's teacher (theme 2). Similarly, theme 3 displayed parents' practices about their involvement at home and in school; while theme 4 explored teachers' perceptions about parents' practices in their class. The fifth theme brings together two codes: parents' and teachers' perceptions about their views of the optimal school-family-community collaboration. Table 2 introduces themes, codes and associated code frequencies.

Table 2

Themes, codes and associated code frequencies for parents and teachers

\begin{tabular}{|c|c|}
\hline Code & Frequency \\
\hline \multicolumn{2}{|l|}{ Theme 1 Teacher involvement } \\
\hline Means of communication used & 49 \\
\hline Forms of volunteering encouraged & 26 \\
\hline Means of encouraging parental support & 47 \\
\hline Means of encouraging involvement in SC & 12 \\
\hline Community resources used & 14 \\
\hline \multicolumn{2}{|l|}{ Theme 2 Parents' perceptions of teacher involvement } \\
\hline Means of communication used by teachers & 100 \\
\hline Forms of volunteering encouraged by teachers & 53 \\
\hline Means of learning at home encouraged by teachers & 78 \\
\hline Means of encouraging involvement in SC used by teachers & 56 \\
\hline Collaborating with community organizations & 27 \\
\hline \multicolumn{2}{|l|}{ Theme 3 Parent involvement } \\
\hline Communicating & 163 \\
\hline Volunteering & 50 \\
\hline Learning at home & 153 \\
\hline Decision-making & 81 \\
\hline Collaborating with the community & 58 \\
\hline \multicolumn{2}{|l|}{ Theme 4 Teachers' perceptions of parent involvement } \\
\hline Means of communication used by parents & 41 \\
\hline Forms of volunteering used by parents & 12 \\
\hline Means of learning at home used by parents & 37 \\
\hline Particiption of parents in school decision-making & 13 \\
\hline Collaboration with the community & 7 \\
\hline \multicolumn{2}{|l|}{ Theme 5 Ideal school-family relationship } \\
\hline Teachers' perceptions & 32 \\
\hline Parents'perceptions & 106 \\
\hline
\end{tabular}


To validate the coding process, an interjudge test was conducted using the software on 15 verbatim. A reliability agreement of 0.87 (Krippendorf's alpha) was obtained between the two coders on $15 \%$ of transcription or 9 verbatims.

\section{FINDINGS}

The results are presented below according to the goals of this study, which aimed to explore the forms of parental and teacher involvement based on the discourse of these actors, and the main elements that make an ideal relationship.

\section{Teacher Involvement}

Forms of TI refer to the means used by the teachers to support parental involvement in learning at home and communicate with parents (cf. Table 2). The results show that the teachers mainly asked the parents to monitor homework (it is agreed with the parents that they must check their child's homework Teacher 12 ) or school projects $(\mathrm{n}=7)$, sign documents $(n=6)$ and read to their children $(n=4)$. Overall, the parents shared the same perceptions regarding the teachers' expectations of them. Thus, 12 parents reported that the teacher had asked them to monitor homework or school projects, 12 sign documents, and $11 \mathrm{read}$ to their child. Some teachers also reported that they did not assign homework $(n=4)$, and the reports of 13 parents confirmed this. The parents $(n=25)$ and teachers $(\mathrm{n}=10)$ both reported that the pupils' homework agenda was the main tool used to guide the parents in helping with learning activities at home.

On the other hand, their views differed regarding the other means used by the teachers to encourage PI. Six teachers reported that tool kits, with accompanying explanations, were provided to parents. However, 18 parents reported that they had not received such tool kits to guide them in helping their child with schoolwork at home, while only four parents reported having received this aid, as this parent reports "the teacher puts several methods which suggest us for example for the spelling of the words, that remains very little but yes there are some" ( parent 39). Similarly, 10 teachers reported that they had provided explanations at the parent-teacher meeting held at the beginning of the school year. However, only five parents reported the same. Moreover, only three teachers reported that they had not requested the parents' help with homework, whereas 18 parents reported that they had not received a specific request from the teacher to help their child with schoolwork at home.

The teachers reported that the means of communication (cf. Table 2) they most often used with parents were the pupils' homework agenda $(n=10)$ and email $(n=8)$. The other means reported were individual parent-teacher meetings to discuss the first report card $(n=6)$, telephone conversations $(n=5)$, other meetings at school $(n=5)$ and a weekly summary report $(\mathrm{n}=5)$. Overall, the parents' perceptions in this regard were fairly similar to those of the teachers. Thus, according to the parents, the means of communication most often used by the teachers were email $(n=30)$ and the pupils' homework agenda $(n=29)$. The parents and teachers both reported that the frequency of contact greatly depended on whether the child was having trouble at school ( $n=7$ of parents; $n=5$, of teachers). Some parents $(n=14)$ reported that they had little contact with the teacher. Another difference regarded conversations on the school site. A greater number of 
teachers $(n=5)$ considered conversations on the school site as a means of communication used, compared to only 3 parents.

Teachers' narratives help picture out the means and actions used by teachers to encourage PI at school through volunteering, participating in the SC and collaborating with the community (cf.Table 2). Seven teachers reported that they encouraged parents to participate through volunteering, as illustrated by this teacher: "they are always welcome in class. I don't mind if they want to come and observe. But it all depends on how they do it" (Teacher6). The main forms of volunteering they suggested were: accompanying the class on outings $(n=9)$; helping in the classroom $(n=6)$; making presentations, helping prepare materials or school shows, and helping in the school library $(n=3)$. On the other hand, four teachers reported that they did not encourage parents to participate through volunteering. As for parental participation in the SC, the invitation in this regard came from the school administrator, according to 11 teachers. With regard to collaboration with the community, according to the results, it appears that teachers focus more on their own efforts to collaborate with the community but no so much on trying to stimulate cooperation between parents and the community. In fact, among interviewed teachers, 10 reported that they strove to find ways to collaborate with community organizations close to their school (community library, youth centre, local health and social services centre, but did not specify whether or not they encouraged parents to participate in this way.

Relatively few parents $(n=17)$ had the impression that they had been encouraged by the teacher to volunteer in the classroom or at school. Only 13 parents stated that they had been invited to accompany the class on school outings, four parents said they had been encouraged to help in the classroom, and four parents reported that they had been asked to help in the school library. Moreover, 24 parents confirmed the teachers' comments regarding participation in the $\mathrm{SC}$, that is, that the invitation in this regard came from the school administrator. As for collaborating with the community, 27 parents reported that such collaboration was not encouraged by the teacher. The results indicate that parents were not really informed of the teachers' efforts in this area.. However, the parents were informed regarding activities such as school outings (community library, museums, etc.).

\section{Parental Involvement}

The results reveal that the forms of PI mentioned by parents and teachers focus on learning at home and communication between partners. (cf. Table 2.) Thus, all the parents reported that they monitored homework/school projects $(n=45)$ (For the school follow-up, when they come back from school, they are entitled to a moment of relaxation but immediately after supper, we start doing homework, this until the sixth grade, and this always accompanied by a parent. We look at the list of homework and lessons to be done and we do a daily follow-up. Parent 6 )and 12 also reported signing documents as requested (homework agenda, exams, etc.). However, only four teachers perceived that the parents monitored homework/school projects and signed documents. Moreover, 13 parents said they read to their children on a regular basis, whereas only three teachers perceived that the parents took on this task. More than half the parents $(n=30)$ reported that they used their child's homework agenda to support the learning activities, 
homework and lessons presented therein. However, only four teachers perceived that the parents used this tool, while four teachers specifically expressed the view that the parents did not.

Slightly over a quarter of the parents $(n=13)$ maintained that they lacked information of a pedagogical nature, but this did not come out in the teachers' narratives - in fact, none of the teachers mentioned it. However, 14 parents said they had asked for advice from the teacher to address this lack of information, and two teachers confirmed that parents had asked for such advice. Moreover, 20 parents said they felt competent to help their child, and only two parents stated they did not feel competent in this regard ("Despite the fact that I'm a teacher with a master's degree in pedagogy and a competency approach, I teach at the CEGEP there, I don't always feel very competent. There's a world out there, teaching children is really a specialty" Parent 5, ). However, five teachers felt that the parents did not have the competencies needed to support their child ("Probably some of the parents are not because they have had difficulties at school themselves; even illiterate parents are suspected" Teacher 3) and only three teachers perceived that the parents felt competent in this way.

Meanwhile, 15 parents said they felt only somewhat competent to help their child. However, six teachers had the impression that the parents felt this way. Lastly, 10 parents reported that they were motivated to support their children. However, only two teachers felt that the parents were so motivated, while four teachers reported feeling that the parents were not. In addition, three teachers felt that the parents did not support their children at home. These results thus bring out differences in the parents' and teachers' perceptions regarding parental monitoring, parental feelings of competence, the parents' motivation to support their children and the lack of pedagogical information.

The means of communication the parents reported using to interact with the teacher were: email $(\mathrm{n}=31)$, the child's homework agenda $(\mathrm{n}=21)$, scheduled or impromptu meetings ( $\mathrm{n}=23$ ) ("the teacher is there early in the morning so I can talk to her directly if there's something going on" Parent 32), the meeting to discuss the first report card $(\mathrm{n}=8)$ and telephone conversations $(\mathrm{n}=11)$. The means of communication used by the parents as perceived by the teachers were: email $(n=13)$, the child's homework agenda $(\mathrm{n}=11)$, scheduled or impromptu meetings $(\mathrm{n}=5)$, the meeting to discuss the first report card $(n=3)$ and telephone conversations $(n=4)$.

The parents reported that they mainly communicated with the teachers by email and through the child's homework agenda. However, they reported that scheduled and impromptu meetings were not an often-used means of communication.

Again with regard to school-family communication, the parents perceived that talking with their child about school and other school-related subjects was an important form of communication. The parents mentioned that the subjects they discussed with their children were: their child's day at school ( $\mathrm{n}=29)$; general topics (cultural knowledge, art, sports, etc.) $(\mathrm{n}=25)$; peer relations $(\mathrm{n}=21)$; and their child's current projects or future plans $(\mathrm{n}=12)$.

Forms of PI such as volunteering, participating in the SC and collaborating with the community were also brought up by the parents. Close to half the parents $(n=21)$ 
reported that they did not volunteer at school and six teachers also considered that the parents did not volunteer at school. However, 15 parents reported that they participated by accompanying the class on school outings and seven teachers considered that the parents participated in this way. Five parents said they helped in the school library, and two teachers had the perception that the parents took on this task. Moreover, seven parents said they helped during some activities in the classroom and two teachers considered that the parents helped in this way.

As for participating in the SC, most of the parents $(n=39)$ reported that they did not get involved in this way and 10 teachers shared this perception. Positions for parents on SCs are limited; nevertheless, three parents in our sample reported participating in these councils and three teachers confirmed this information. Moreover, 35 parents and 12 teachers asserted that the invitation to participate in the SC came from the school administrator, as indicated by this quote, "Rather, it is the school principal who makes the request at the beginning of the year" (Teacher 5).

The parents reported collaborating with the community in the following ways: 20 parents used the community library, 16 parents took part in community centre activities, and 13 parents visited museums. Moreover, two teachers said that parents used the community library and three teachers reported that parents took part in community centre activities, while six teachers said they did not have any information regarding the parents' collaboration with the community.

The results also reveal the main characteristics of the ideal relationship between the actors, as perceived by them. It mainly emerged that, for both the parents $(n=27)$, and teachers $(n=6)$, regular and continual communication was key to a collaborative relationship. Moreover, both the parents $(n=12)$ and teachers $(n=6)$ underlined mutual trust as another crucial characteristic of an ideal relationship. However, the parents $(n=7)$ also specifically emphasized mutual respect and felt that ideal collaboration depended on the teacher $(n=7)$.

The results indicate similar perceptions among the two groups of actors regarding two important factors: 13 parents and three teachers stated that it was important to share the same goals, while 19 parents and five teachers considered that the school and family should work as a team and cooperate to a greater extent to make their relationship truly collaborative.

\section{DISCUSSION}

Convergences and Discrepancies in School-Family Community Collaboration Practices

The first objective of this article was to analyze whether the collaborative practices between parents and teachers were convergent. In general, it appears that, in view of parents' and teachers' narratives, that SFC collaboration practices are mainly focused on learning at home, school-home communication and, occasionally, volunteering. This is not surprising because these two types of activities are often identified by researchers (Larivée, 2019) as being the most important for parents as well as for school employees.

Given the results, it appears home-based learning is a practice favored by parents and teachers. Based on the results of this research, it appears that parents help their children 
with homework in different ways. Many parents emphasized the children's autonomy, for example, by encouraging their children to find solutions themselves. Other parents provided close support, helping their children through all the steps of their homework; rather than simply playing a monitoring role, their support involved a detailed review of the lessons and content learned at school. The parents' understanding of learning at home appeared to be influenced by several factors: their own experience, the difficulties experienced by their children, the level of difficulty of the schoolwork, the amount of homework assigned, whether it was an exam period, etc. Some parents saw helping with homework as an opportunity to spend quality time with their children, a chance to share and exchange ideas on various subjects, including schoolwork. The results show that homework help does not necessarily represent a source of tension between parents and children. Indeed, we believe that it is how parents support learning at home that can make a difference as Boonk et al. (2018) have also suggested.

The child's homework agenda was recognized by both the parents and teachers as the main tool used to guide learning at home. This tool was used by teachers to set down in writing the homework and lessons assigned to the children and helped parents organize and structure their support at home. It thus appeared to serve both communication and planning purposes for teachers and parents. The teachers also reported other means of supporting parents in helping with learning at home, mainly the tool kit and the parentteacher meeting at the start of the school year. However, the parents referred to these tool kits less often than the teachers, probably because they were less familiar with them or did not recall having received them. Moreover, some parents deplored a lack of information of a pedagogical nature. They expressed a desire to be better informed regarding the new teaching methods used, as summed up in the following excerpt:

Another problem is the pedagogical approaches, which aren't always accessible to parents, even for me, and I come from a teaching background. The approaches have changed so much that it's hard for us to follow sometimes. Often, you have to wait for teacher-parent meetings to have your questions answered but the meetings are usually held quite a while after the beginning of the school year. (Parent B6)

Thus, the parents developed other strategies, such as scheduling an appointment to meet the teacher. Other parents attempted to get by on their own, relying on their own competence.

Communication is another dimension for which the views of teachers and parents seem to align. These actors reported using the same means of communication, namely, email, the child's homework agenda and face-to-face meetings. However, their opinions differed regarding the frequency of contact. The results of the analysis show that there are two compulsory meetings during the school year: the collective meeting at the beginning of the school year and the individual meeting scheduled to discuss the first report card, held at the end of November in Quebec. Otherwise, the meetings were ad hoc, depending on the child's needs or difficulties. This was insufficient, from the perspective of the parents, with almost a quarter of parents bringing up the lack of communication or little contact they had with the teacher. This perception that the number of meetings was insufficient did not, however, come up in the teachers' 
discourse. We believe that these results bring out the importance for schools of reviewing the means and frequency of communication between parents and teachers. In line with previous studies (Deslandes 2020; Lewis et al, 2011), this study suggests that communication between the school and families should be more regular, more frequent and better adapted to the needs of parents.

With regard to communication, most parents reported that they regularly conversed with their children at home. They thus paid particular attention to such communication, whereas the teachers generally did not refer to it at all. It is possible that the teachers did not wish to interfere in the parents' role. However, several researchers (Lamboy \& Guillemont, 2014) have noted that when parents show an interest in their children and regularly converse with them, this has an impact on their children's schooling and the parents' involvement at school. Knowing the positive effects of parent-child communication (e.g. Boonk et al., 2018), it is desirable for teachers to encourage such discussions, particularly about what children are learning and their social relationships at school

With regard to the results, several topics structure parent-child communication. The child's day at school was the main subject of conversation between the parents and children. Parents sought to find out more about their child's progress and day-to-day experiences at school, and their relationship with their teacher. This was another strategy adopted by the parents to find out what their children were learning and about their conduct at school. Moreover, according to the parents' discourse, the subjects of discussion at home included general knowledge, the child's social relations (ex. with peers, the teacher) and upcoming school projects. This reveals another facet of parental involvement with children that teachers can encourage. This finding is important because communication between parents and children regarding school has the most consistent and positive relations with academic achievement (Boonk et al., 2018

The results of the narratives analysis brought out interesting findings regarding volunteering, participating in the SC and collaborating with the community. Thus, almost a quarter of the parents volunteered by accompanying the class on outings, as the teachers' mainly encouraged this form of volunteering. However, overall, parental involvement in the classroom or at school was not frequent and neither were invitations from the teacher in this regard. This observation thus still applies today. Several factors may be involved, but lack of time seems to be a factor that parents and school staff regularly raise (Larivée, 2019).

In the same vein, it must be noted that the parents did not often participate in the school council (SC). Almost all the parents and most of the teachers asserted that the invitation for the parents to participate in the SC came from the school administrator. Aside from the fact that places for parents on SCs are limited, since the parents' participation remains so low, questions should perhaps be raised regarding these issues, such as the way parents are invited to participate, the role of the school administrator, etc. Some parents reported that they did not have time to participate or that their schedules were not compatible with SC meetings. However, on a more fundamental level, the parents questioned the usefulness of their participation in the SC given the role played by this 
council and the way it operated. Those parents who participated in the SC said their real interest in participating was to find out more about their child's school environment, learn how the school operated, get to know the teachers better and get closer to the school. Indeed, Hill \&Tyson (2009) showed that PI in school activities has an impact on the quality of parent-teacher contacts. However, based on their experience, the parents in those studies also reported feeling that their participation in the SC served no purpose as shown in the following excerpt:

Very few parents participate ... I think there are two things, a lack of time, that's obvious... There's also a lack of information. Parents are asked to get involved, they're invited to communicate with the school but I think, in the end, the parents tell themselves they have no role to play... that's what I think too, there are no guidelines, we feel there's no room for us, we have no say in it, we can't really intervene... (Parent F4)

As for the last dimension, collaborating with the community, the parents and teachers appeared to get involved this way separately. On the one hand, the parents said the teachers did not encourage them to collaborate with the community, or inform them regarding the community resources they might benefit from. However, the parents reported that they did use the community library, visit museums and take advantage of the services provided by community centres, etc. The parents got involved in these activities solely on their own initiative, based on their children's desires and preferences - there was no link with the school. For their part, the teachers said they made an effort to collaborate with the community organizations near the school. Thus, the teachers used the community library, youth centre, and services provided by the CLSC or other community resources (retirement home, gardening centre, etc.). However, our analysis did not indicate whether the teachers encouraged the parents to collaborate with these community organizations. In fact, volunteering, participating in the SC and collaborating in the community, neither the teachers nor the parents perceived these as a viable form of parental involvement. The teacher's role in promoting these forms of parental collaboration thus appears to be important. This brings up the question of pre-service teacher training (Larivée, 2008). Teachers could be made more aware of the effects of SFC partnerships and the practices favoured by parents during initial teacher training, but also through professional development activities. This would better equip teachers to play a leadership role in SFC partnerships, as recommended by Sheldon \& Epstein (2005) and Hoover-Dempsey et al. (2010).

To sum up, parents and teachers showed points in common with regard to the forms of their involvement. Learning at home and communication were the main dimensions of involvement mentioned. The parents and teachers were in agreement regarding the tasks to be accomplished, such as monitoring homework, signing documents, etc. Differences appeared regarding the means provided by the teacher to support the parents. Most parents and teachers agreed that the main tool used was the child's homework agenda. However, the parents reported being given few other tools and insufficient pedagogical information or explanations relating to the learning objectives. With regard to communication, overall, the parents and teachers reported using the same means of communication (email, the child's homework agenda, meetings). However, the parents 
expressed a desire for more regular and continuous communication on the part of teachers, whether or not their children were having trouble at school. As for volunteering, most parents said the teachers only encouraged their participation in school outings. With regard to parental participation in the SC, most of the parents said they did not participate in these councils due to a lack of time, but also because they did not feel they had any real power over the way they operated. With regard to collaborating with the community, the parents and teachers did not appear to view this form of involvement the same way.

\section{Characteristics of an Effective School-Family Relationship According to Parents and} Teachers

The second objective of this article was to track the solutions that parents and teachers put forth to build an effective SFC relationship. Given the research results, it appears the actors suggested interesting avenues and shared similar opinions regarding some principles: communication, shared goals, and mutual understanding, trust, and openness. However, some qualifications are in order.

Regular communication constituted the key to the ideal school-family relationship for both actors. The parents expressed a desire for the teacher to communicate regularly with them regarding their children's learning and conduct at school, and to inform them as soon as a problem came up, so that they could work together with the teacher to solve it. The parents expressed a desire to be more involved at school, which matched the teachers' desire in this regard, although fewer teachers expressed it. Moreover, the parents also stated that teachers and parents should collaborate with one another to a greater extent. However, this desire did not appear to be widely shared by the teachers.

Similarly, other characteristics of the teacher-parent relationship, more contextual and interpersonal in nature, were considered by the actors to be necessary for the construction of a positive relationship: mutual trust, openness, respect, and understanding between the partners. Indeed, these criteria, mentioned by both parents and teachers as being desirable for creating the favourable conditions for SFC partnerships, emerged precisely from the difficulties that the partners had experienced in their relationship. This observation on the part of parents and teachers underscores the fact that this relationship depends as much on teachers as on parents. Indeed, this underlines the fact that it is more in terms of relationship than of partnership that parents-teachers relations must be described (Arapi, 2017; Deslandes 2020). The teacher-parent relationship is, above all, contextual, oriented by the individual characteristics of each party. In other words, it is primarily a human relationship, as summed up in the following excerpt:

I think it always comes down to the challenges of a human relationship, so there's a difference between what you mean, what you want to say, what's perceived, or decoded, what should be said, what someone really means, but what can't be said in some circumstances. It's always an area where human relationships are more difficult, between what I want to hear and the message the teacher wants to give me. There's always, there can be a clash - what I don't want to hear. I don't want to hear that my son has $\mathrm{X}$ health problem or behavioural problem or learning 
difficulty. I could say my relationship with the teacher isn't good, but actually it's just my perception, it's me to some degree. This conflict comes from myself, not just from the teacher... It's a human relationship... (Parent D24)

\section{CONCLUSION AND IMPLICATION}

The discourse of the actors brought out their practices relating to SFC partnerships. Both actors reported that learning at home and teacher-parent communication were the practices of partnership they favoured. They were in agreement regarding the tasks to be accomplished, but differences emerged regarding the means provided by the teachers to support the parents. The parents said the teachers provided them with few tools and insufficient pedagogical information or explanations regarding the learning objectives. The partners used the same means of communication, but the parents felt that communication with the teachers was not frequent enough. As regards PI at school, the parents mainly participated by accompanying the class on school outings. The parents did not often participate in the SC, undoubtedly because, aside from the limited number of places made available for them, they also doubted that their input in this council would make a difference.

This study contributes to the literature by exploring not only the perceptions of parents and teachers, but also the practices and means put in place by these partners to foster mutual collaboration. To our knowledge, few studies have examined the practices of both parents and teachers concurrently. The Epstein model here appears to be working, but local parameters like school culture and community culture must alos be taken into account.

This study helped to better understand the perspectives of parents and teachers on the school-family relationship. Based on this study, recommendations can be formulated. Thus, communication is seen as the cornerstone of this relationship by the participants. Teachers may consider sending personal weekly notes through the school diary to parents, sending collective messages to parents through the class site (on learning done in class, information about class life, etc.). Another suggestion for communicating with parents is to make phone calls or virtual appointments when the parents cannot come to school. In connection with learning at home, we suggest providing parents with explanations (how to do active reading with the child) and tools (eg steps for problem solving) in connection with learning strategies throughout the year and not on an ad hoc basis. A weekly collective mail to all parents could be a tool to explore as well as a class website. Widening the scope of parental involvement can be a step towards an effective school-family relationship. Inviting parents to observe in class or providing occasional help could be an opportunity to get to know each other better and to build a bond of trust between the actors. Parents are not always aware of what is going on in the classroom and it will be an opportunity to see the extent of the work being done by the teacher. Likewise, as the participants of this study expressed, the presence of parents at school is also sending message to children: school is important.

Nevertheless, this study has some limitations. One limitation is the make-up of the sample, as the majority of parent participants came from affluent backgrounds. It was thus not possible to determine whether differences could be found in the practices of 
parents from different backgrounds. This could constitute an avenue for future research, that is, analyzing the practices of the teacher in reference to the practices of the parents of the children in their classrooms.

\section{REFERENCES}

Addi-Raccah, A., \& Grinshtain, Y. (2018). Teachers' capital in view of intensive parental involvement in school: The case of teachers in high socio-economic status schools in Israel. Research Papers in Education, 33(5), 599-619.

Arapi, E. (2017). Implication des parents et des enseignants: quel lien avec la réussite scolaire des élèves du primaire? (Doctoral dissertation, Université Laval). http://hdl.handle.net/20.500.11794/28124

Bæck, U. D. K. (2010). 'We are the professionals': a study of teachers' views on parental involvement in school. British Journal of Sociology of Education, 31(3), 323335 .

Boonk, L., Gijselaers, H. J., Ritzen, H., \& Brand-Gruwel, S. (2018). A review of the relationship between parental involvement indicators and academic achievement. Educational Research Review, 24, 10-30.

Boulanger, D., Larose, F., Grenier, N., Doucet, F., Coppet, M. \& Couturier, Y. (2014). Les discours véhiculés dans le champ du partenariat école-famille-communauté: analyse de la documentation scientifique. Service social, 60(1), 119-139.

De Saedeleer, S., Brassard, A. \& Brunet, L. (2004). Des écoles plus ouvertes à l'implication des parents? Le point de vue des directeurs d'établissement au Québec. Revue française de pédagogie, 147(1), 69-77.

Deslandes, R. \& Barma, S. (2015). Les relations entre les enseignants et les parents: premières étapes d'intervention d'un Laboratoire du Changement. Revue internationale $d u$ CRIRES: Innover dans la tradition de Vygotsky, 3(1), 20-34.

Deslandes, R. \& Bertrand, R. (2005). Parent involvement in schooling at the secondary level: Examination of the motivations. The Journal of Educational Research, 98(3), 164-175.

Deslandes, R. \& Rivard, M. C. (2011). Perceptions d'éducateurs à l'égard de parents en matière d'évaluation des apprentissages au primaire. Éducation et francophonie, 39(1), 133-155.

Deslandes, R. (2020). School-Family-Community Collaborations. Retrospective on what has been done and what has been learned. Volume 1. School-Family Relations.

Dor, A., \& Rucker-Naidu, T. B. (2012). Teachers' attitudes toward parents' involvement in school: Comparing teachers in the USA and Israel. Issues in Educational Research, 22(3), 246-262.

Epstein, J. L. (2011). School, family, and community partnerships. Your handbook for Action. Thousand Oaks: Corwin Press/Sage. 
Epstein, J. L. \& Van Voorhis, F. (2001). More than minutes: Teachers' roles in designing homework. Educational psychologist, 36(3), 181-193.

Hill, N. E. \& Tyson, D. F. (2009). Parental involvement in middle school: a metaanalytic assessment of the strategies that promote achievement. Developmental psychology, 45(3), 740-763.

Hoover-Dempsey, K. V., Whitaker, M. \& Ice, C. (2010). Motivation and commitment to family-school partnerships. In S. L. Christenson and A. L. Reschly (ed.), Handbook of school-family partnerships (pp. 30-60). New York: Routledge.

Kanouté, F. \& Calvet, N. L. (2008). Les relations école-familles immigrées au Québec et en Catalogne. Éducation et francophonie, 36, 161-176.

Karbach, J., Gottschling, J., Spengler, M., Hegewald, K. \& Spinath, F. M. (2013). Parental involvement and general cognitive ability as predictors of domain-specific academic achievement in early adolescence. Learning and Instruction, 23, 43-51.

Karsenti, T., Larose, F. \& Garnier, Y. D. (2002). Optimiser la communication familleécole par l'utilisation du courriel. Revue des sciences de l'éducation, 28(2), 367-390.

Krippendorff, K. (2004). Content Analysis: An Introduction to Its Methodology. Thousand Oaks: Sage.

Lamboy, B. \& Guillemont, J. (2014). Développer les compétences psychosociales des enfants et des parents: pourquoi et comment? Devenir, 26(4), 307-325.

Larivée, S. (2011). Regards croisés sur l'implication parentale et les performances scolaires. Service social, 57(2), 5-19.

Larivée, S. (2012). L'implication des parents dans le cheminement scolaire de leur enfant. Comment la favoriser? Éducation et Formation - e-297, 33-47.

Lewis, L. L., Kim, Y. A., \& Bey, J. A. (2011). Teaching practices and strategies to involve inner-city parents at home and in the school. Teaching and Teacher Education, 27(1), 221-234.

Miles, M., Huberman, M., \& Saldana, J. (2013). Qualitative Data Analysis: A Methods Sourcebook. Thousand Oaks: Sage

Organisation for Economic Co-Operation and Development [OECD] (2010). Education Today 2010: The OECD Perspective. Paris: OECD Publications.

Sheldon, S. B. \& Epstein, J. L. (2005). Involvement counts: Family and community partnerships and mathematics achievement. The Journal of Educational Research, 98(4), 196-207.

Wilder, S. (2014). Effects of parental involvement on academic achievement: a metasynthesis. Educational Review, 66(3), 377-397. 